\title{
EMPRESÁRIOS, O GOVERNO DO PT E O DESENVOLVIMENTISMO
}

\author{
Luiz Carlos Bresser-Pereira
}

\begin{abstract}
RESUMO
Este artigo discute o problema do desenvolvimentismo no Brasil nos governos do PT. Até que ponto, no quadro do governo Lula e do governo Dilma, os empresários industriais logram se distinguir dos capitalistas rentistas e formar, com os trabalhadores e a burocracia pública, uma coalizão de classes desenvolvimentista. Minhas hipóteses decorrem de minha teoria sobre o papel das coalizões de classe ou desenvolvimentistas ou liberais. Os dados estão disponiveis na imprensa. Creio que ficaram claros os esforços dos governos do PT de se apoiar em uma coalizão de classes desenvolvimentista, e o relativo fracasso desse esforço, já que o obstáculo principal ao desenvolvimento econômico brasileiro (o câmbio cronicamente sobreapreciado) não foi superado, devido à falta de apoio na sociedade na sociedade brasileira para uma depreciação elevada e permanente.
\end{abstract}

PALAVRAS-CHAVE: desenvolvimentismo; coalizões de classes; empresários; liberalismo econômico; governos petistas.

\section{INTRODUÇÃO}

Há duas formas de organização econômica e política do capitalismo, o liberalismo econômico e o desenvolvimentismo. Embora a alternativa desenvolvimentista não esteja clara para a maioria, porque, tanto pelos liberais quanto pelos socialistas, fomos sempre levados a pensar que a alternativa ao liberalismo era o socialismo, mas, na verdade, dentro do capitalismo, o que vimos foi, no século $\mathrm{XX}$, a substituição do liberalismo econômico pelo desenvolvimentismo, aqui entendido como uma intervenção moderada do Estado na economia e nacionalismo econômico ${ }^{1}$. Tomando-se a Inglaterra e a França como referências, por passarem por todas as fases do capitalismo sem haver sobreposição entre elas, verificamos que o mercantilismo dos séculos XVII e XVIII foi o tempo do primeiro desenvolvimentismo; entre 1830 e 1929, o capitalismo foi liberal; depois de uma grande crise financeira e econômica e da Segunda Guerra Mundial, os "30 Anos Dourados do Capitalismo" foram o segundo desenvolvimentismo agora um desenvolvimentismo socialdemocrático -, e os "30 Anos Neoliberais do Capitalismo", encerrados em 2008, foram o tempo do segundo liberalismo econômico. A revolução nacional e industrial brasileira, entre 1930 e 1980, ocorreu no quadro de um sistema desenvolvimentista; durante os anos 1990, quando o

\footnotetext{
1 Esta substituição ocorreu a partir da Grande Depressão dos anos 1930 e se manifestou de forma clara nos Anos Dourados do Capitalismo do após guerra.
}

neoliberalismo atingiu plena hegemonia nos Estados Unidos e, a partir dele, no mundo, o Brasil cedeu ao liberalismo econômico, mas desde meados dos segundo governo Lula, estamos assistindo a uma tentativa de se estruturar o capitalismo brasileiro também como um novo desenvolvimentismo socialdemocrático e, agora, também ambiental.

Para avaliarmos esta mudança, devemos examinar o que vem acontecendo desde 2003, quando o Partido dos Trabalhadores (PT) assumiu o governo do país e vem procurando associar trabalhadores e empresários industriais. Uma política desenvolvimentista só alcança êxito quando uma coalizão de classes envolvendo empresários industriais, trabalhadores e burocracia pública fazem um acordo social. Para isto é necessário distinguir os capitalistas empresários dos capitalistas rentistas - o que nem sempre é possível fazer. Em alguns momentos os empresários se distinguem com clareza dos rentistas, porque enquanto os primeiros defendem uma taxa de juros baixa, uma taxa de câmbio competitiva que estimule sua acumulação de capital, os rentistas querem juros nominais altos e inflação baixa para assegurar juros reais altos, e apoiam a política de apreciação cambial para combater a inflação (essa é a política de "âncora cambial"), apoiados, naturalmente, pelos financistas que administram sua riqueza. Quando essa distinção é lograda, não obstante a superposição de papeis entre empresários e rentistas, o liberalismo econômico é deixado de lado, e configuram-se uma política desenvolvimentista e uma estratégia nacional de desenvolvimento. Este trabalho avalia a hipótese de que essa separação está em ocorrendo atualmente. 
Este artigo, publicado na Revista de Sociologia e Política, trata insistentemente sobre a taxa de câmbio, porque estamos convencidos que só quando a sociedade brasileira se der conta de que uma taxa de câmbio competitiva é essencial para o desenvolvimento do país, o Brasil poderá voltar a crescer de forma acelerada. Uma taxa de câmbio competitiva é essencial, porque uma taxa de câmbio crônica e ciclicamente sobreapreciada, como é a taxa de câmbio em países em desenvolvimento que não têm uma política cambial firme, desestimula os investimentos. Ora, o desenvolvimento econômico é, essencialmente, consequência dos investimentos, dados, naturalmente o nível de educação e a capacidade de absorção de tecnologia da população. Metaforicamente, pode-se considerar a taxa de câmbio como um interruptor de luz que liga ou desliga as empresas competentes do país de seu mercado. Desde 1991, o Brasil perdeu capacidade de administrar sua taxa de câmbio, e, principalmente por isso, o Brasil não logrou retomar as elevadas taxas de crescimento que teve entre 1930 e 1980 .

\section{O PT NO PODER}

Quando, no final de 2002, Luiz Inácio Lula da Silva foi eleito presidente, imaginou-se que talvez estivesse então se formando um novo pacto político popular e nacional, mas os dois primeiros anos do governo não confirmaram essa previsão. Sabia-se que o novo presidente teria que fazer um compromisso com as classes dominantes capitalistas e tecnoburocráticas. Isto aconteceu com todos os partidos socialistas que chegaram ao poder através do voto, e não poderia deixar de acontecer com o PT. Mas, ao contrário do que pensa um analista arguto como Tales Ab'Sáber (2011), isto não significava que as concessões de Lula ao capitalismo fossem de tal monta que o tornassem também o representante da grande burguesia inclusive de sua fração financeira. Que, dado seu "claro desejo de articular extremos", ele, "além de constelar as classes muito pobres em seu projeto político... Lula também cooptou amplamente os muitíssimos ricos" (idem, p. 19) . A frase de um grande banqueiro, no momento da reeleição, que Ab'Sáber cita para fundamentar sua tese, é enganadora. $\mathrm{O}$ fato que ele tenha dito que não fazia diferença se fosse Lula o eleito ou seu opositor conservador do PSDB não significa que ele e muito menos a grande burguesia que ele representava houvesse aderido a Lula. Significava, apenas, que a classe dominante havia perdido o "medo de Lula", que presidira sua primeira eleição. E Lula é um líder político suficientemente capaz para não acreditar que ele poderia lograr o consenso da sociedade brasileira. Mas para ele era essencial associar-se aos setores mais progressistas da burguesia, especificamente aos empresários industriais, que haviam sido marginalizados no governo anterior. Por um momento, nos dois primeiros anos de seu governo, sua submissão à política macroeconômica da ortodoxa e liberal pareceram desautorar essa interpretação, mas esse foi um recuo estratégico de um líder político que sabe que a política é a arte do compromisso.

Desde o início de seu governo, Lula procurou liderar um novo pacto nacional. Com esse objetivo criou um órgão formal - o Conselho de Desenvolvimento Econômico e Social da presidência da República - para o qual chamou um representativo número de empresários, de líderes sindicais, de líderes associativos, de burocratas públicos e de intelectuais. Assim, dava a seu governo um caráter pluriclassista. Foi, entretanto, apenas a partir do terceiro ano de seu governo, então já cercado de um número maior de ministros e assessores nacionalistas e de esquerda, que esse objetivo começou a ganhar contornos. A tarefa não era fácil dada a complexidade e heterogeneidade da sociedade brasileira, e dada a dependência de nossas elites. Mas no ano seguinte e, em seguida, no governo Dilma, muito se avançou na direção de um novo pacto nacional e popular. Ao invés de se falar do "fim da era Vargas" (um bordão do Pacto Liberal-Dependente de 1991) começou-se a falar em uma era Vargas renovada, na qual o Estado voltava a ter um papel indutor na economia, a estratégia nacional de desenvolvimento passava a ser desenvolvimentista, e se buscava de forma deliberada um grande entendimento entre as frações de classe progressistas do país.

O fortalecimento de Lula ocorreu quando, diante da crise do Mensalão, ele não ficou apenas na defensiva. Ele adotou toda uma série de medidas concretas em benefício dos muito pobres, e, ao invés de se esconder no Palácio do Planalto, amedrontado pela crise, partiu de forma decidida em busca do apoio popular, usando para isso todas os artifícios da sua retórica popular. $\mathrm{O}$ resultado dessa estratégia foi o surgimento do "lulismo" que André Singer (2009; 2011) analisou com rara acuidade. A massa de eleitores que nas três eleições presidenciais anteriores em que fora derrotado havia votado em candidatos conservadores, e que na sua primeira eleição ainda se dividira entre Lula e o candidato conservador, na sua reeleição vota nele em massa. À liderança política ideológica que Lula demonstrara nas grandes greves do ABC de 1978 e 1979 e na condução do PT acrescentava-se agora uma liderança populista e carismática através da qual ele passava a falar diretamente com as massas, sem a intermediação de ideologia ou de partido político. André Singer apenas se engana quando afirma que esse grande subproletariado em ascensão econômica e social é "conservador". O que ele vem mostrando, em 
sucessivas eleições presidenciais, não é que ele seja conservador ou progressista, mas que ele sabe em quem votar. Ele espera do governo segurança e amplos serviços sociais. Votou em Collor, porque se decepcionou com os políticos que comandaram a transição democrática quando estes falharam em controlar a alta inflação com o Plano Cruzado; voltaram em Fernando Henrique, porque este lhes garantira a estabilização dos preços; passaram a votar, mas agora com mais energia, em Lula e depois na sua sucessora, porque Lula atendeu objetivamente a suas demandas, e soube falar com as massas como ninguém falara antes, nem mesmo Getúlio Vargas.

Para entendermos o significado político do governo Lula é um equívoco reduzi-lo à corrupção e à incompetência, como faz a direita, porque sabe que foi um governo de esquerda; é também um equívoco afirmar, como faz um crítico de esquerda como Francisco de Oliveira (2010), que esse governo não representou qualquer mudança política significativa, que foi um episódio de "hegemonia às avessas"; terceiro, é um equívoco acreditar que seu governo como os primeiros dois anos e meio do governo Dilma Rousseff são um exemplo de desenvolvimentismo social bem sucedido, como muitos acreditam. A versão da direita está presente em toda a grande mídia brasileira. A interpretação da esquerda crítica representada por Francisco de Oliveira diz o seguinte: "o consentimento se transforma no seu avesso: não são mais os dominados que consentem em sua própria exploração; são os dominantes - os capitalistas e o capital, explicite-se - que consentem em ser politicamente conduzidos pelos dominados, com a condição que a 'direção moral' não questione a forma da exploração capitalista" (idem, p. 27). Seguindo uma linha semelhante, Filgueiras et alli (2010), partindo da premissa que o antigo desenvolvimentismo como o novo não são outra coisa senão a afirmação do "tripé capital internacional, Estado e capital nacional, agora sob a hegemonia do capital financeiro", concluíram que "a decisão política de 'retorno' do Estado ao processo econômico e o consentimento dos setores subalternos permitiram a Lula acomodar e compatibilizar interesses potencialmente conflitantes." (idem, p.39)

Esta tese pode fazer sentido para quem acredita que o socialismo seja uma alternativa concreta e real ao capitalismo aqui e agora. Se esta tese infelizmente não é verdadeira, se não há espaço para o socialismo democrático, o exercício da política, quando esta não é mera crítica, mas construção social, tem que pensar em um capitalismo melhor, menos injusto e mais eficiente. E, para entender esse fato, é importante a distinção lembrada por Carlos Nelson Coutinho (2010), no livro que reproduziu os trabalhos apresentados a um seminário para discutir a tese da hegemonia às avessas, que Antonio Gramsci fez entre a grande e a pequena política. Dada essa distinção, o que é a grande política hoje? Apenas aquela que põe em confronto capitalismo e socialismo, ou, mais razoavelmente, aquela que põe em confronto o neoliberalismo e um desenvolvimentismo social? A grande política é aquela que apresenta alternativas verdadeiras para o eleitor. Se o socialismo não está no horizonte do possível, a grande alternativa histórica dentro do capitalismo foi e continua a ser até hoje a alternativa entre o neoliberalismo, entendido como ideologia e organização econômica baseada no liberalismo econômico, e o desenvolvimentismo, que supõe uma coalizão de classes voltada para o desenvolvimentismo - um desenvolvimentismo que nas suas fases iniciais é apenas econômico, mas depois, graças à luta dos trabalhadores ou dos pobres, tende a ser democrático e social, e mais tarde ainda, ambiental.

A tese da esquerda radical é a contrapartida à tese neoliberal segundo a qual o governo Lula nada mudou de substancial em sua política econômica - algo que, se fosse verdade, não permitiria explicar a oposição radical que a direita fez ao governo Lula e hoje faz ao governo Dilma. Na verdade, o governo Lula a partir do final do seu primeiro mandato e agora o governo Dilma representam uma verdadeira alternativa ideológica e de organização econômica ao neoliberalismo - uma alternativa de desenvolvimentismo social. Mas isto não significa que venha sendo uma tentativa bem sucedida. Não é, certamente, a alternativa bem sucedida do ponto de vista econômico, dado que para dobrar durante pouco tempo a taxa de crescimento durante uns poucos anos, valeu-se do aumento do preço internacional das commodities exportadas pelo país. Foi, sim, bem sucedida do ponto de vista distributivo. Mas aspirações e critérios pessoais são irrelevantes no julgamento de uma questão como essa. O que é importante é compreender que os elementos essenciais do desenvolvimentismo estão presentes - a intervenção moderada na economia através do planejamento dos investimentos nos setores não competitivos ou pouco competitivos da economia, e uma ativa política econômica e social. Um desenvolvimentismo que, por ser democrático e social, encontra a repulsa da direita, do capital rentista e financeiro, da classe média propriamente dita amedrontada pela emergência da "nova classe média" - na verdade da classe baixa que chega ao consumo de massas. Uma direita que, no início do governo Lula, como no início do governo Lula, tentou cooptar os novos governantes. Mas, como não o conseguiu plenamente - conseguiu apenas que os compromissos ou concessões mútuas fossem realizados - a fase de cooptação, na qual essa direita 
consente aparentemente em ser politicamente conduzida pelos dominados, terminou, e, como vimos nas eleições presidenciais de 2010, e, em 2012, na segunda crise do Mensalão, a do julgamento pelo Supremo Tribunal Federal, essa direita neoliberal jogou-se com todas as suas forças contra o governo e o Partido dos Trabalhadores, desmentido a tese de Francisco de Oliveira (2007, p. 22) da "irrelevância da política partidária no capitalismo contemporâneo".

No plano econômico, o governo Lula deixou muito a desejar porque seu desenvolvimentismo foi marcado pelo populismo cambial. A taxa de câmbio, que primeiro dia do seu governo, em janeiro de 2003 , era de $\mathrm{R} \$$ 6,00 por dólar, a preços de 31 de dezembro de 2010 , nessa data caíra para $\mathrm{R} \$ 1,65$ - uma taxa de câmbio extremamente apreciada, já que as boas estimativas apontam para uma taxa de câmbio de equilíbrio industrial de R\$ 2,75 (Marconi, 2012). Esta brutal sobreapreciação cambial inviabilizou a indústria brasileira, e acelerou uma desindustrialização que vem ocorrendo desde os anos 1980. O mercado interno que foi criado pela política distributiva do governo foi em pouco tempo capturado pelas importações - o que deixou claro o equívoco daqueles que acreditavam que seria possível um desenvolvimento com taxa de câmbio apreciada desde que fosse voltado para o mercado interno.

A presidente Dilma Rousseff não logrou atender à demanda fundamental da macroeconomia estruturalista do desenvolvimento - superar a armadilha da taxa de juros elevada e da taxa de câmbio sobreapreciada mas se identifica com o desenvolvimentismo. Em 20 de abril, em discurso na formatura de novos diplomatas, a presidente declarou que para se desenvolver o Brasil precisa equacionar as três amarras do país: taxa de juros alta, câmbio e impostos altos. Não é, porém, fácil implementar uma estratégia nacional novo desenvolvimentista, que está baseada em (1) baixo nível de taxa de juros, em torno do qual gire a política monetária; (2) responsabilidade cambial ou taxa de câmbio que flutue em torno do nível de equilíbrio industrial, tornando competitivas as empresas que utilizam tecnologia no estado da arte mundial; e (3) responsabilidade fiscal. Foram realizados esforços nessa direção, mas insuficientes. Nos dois primeiros anos do governo Dilma a taxa de câmbio foi depreciada de $R \$ 1,65$ para cerca de $R \$ 2,00$ - o que foi um avanço, mas continuou ainda longe da taxa de câmbio de equilíbrio industrial, que deve ser de aproximadamente $\mathrm{R} \$ 2,90$ por dólar ${ }^{2}$. Uma série de medidas de política

\footnotetext{
2 Nelson Marconi (2012) calculou a taxa de câmbio de equilíbrio industrial em $\mathrm{R} \$ 2,75$ por dólar. Considerando-se uma inflação de $6 \%$, em 2013 dever ser de R $\$ 2,915$ por dólar, ou, arredondan-
}

industrial vêm procurando contrabalançar a sobreapreciação cambial (a desoneração de encargos trabalhistas diversos setores industriais, o corte da tarifa de energia, a aceleração das concessões das obras de infraestrutura, a continuidade da política de redução do IPI, a continuidade da política de escolha de campeões nacionais pelo BNDES) mas elas são naturalmente incapazes de compensar o câmbio sobreapreciado. Quando, em agosto de 2011, o Banco Central surpreendeu o mercado financeiro e reduziu a taxa de juros, argumentando que a grave crise do euro estava desaquecendo a economia brasileira, os representantes da ortodoxia liberal imediatamente protestaram, prognosticando a retomada da inflação, mas em pouco tempo ficou óbvio que o Banco Central estava agindo na linha correta. No plano macroeconômico, além de baixar a taxa básica de juros, o governo continuou com a política de controle da entrada de capitais $^{3}$, e teve a coragem de eliminar o piso de juros reais para as cadernetas de poupança que constituíam um velho empecilho legal a novas baixas da taxa de juros. É cedo ainda (junho de 2013) para avaliar o governo Dilma, mas há indicações de que estamos diante de uma governante competente, dotada de espírito público e desenvolvimentista, que, porém, não teve forças para enfrentar o obstáculo fundamental ao desenvolvimento econômico do país: a taxa de câmbio cronicamente sobreapreciada desde 1991, quando o governo Collor abriu o país financeiramente.

\section{O PROBLEMA DA PRIORIDADE DO CONSUMO}

Para se formar um pacto desenvolvimentismo não basta a vontade do governante. A partir da perspectiva da sociologia política, é preciso considerar o papel dos trabalhadores, da burocracia pública e dos empresários industriais. E, mais amplamente, é preciso avaliar se a sociedade brasileira está disposta a abandonar a prioridade que vem dando ao consumo no curto prazo, que a vem caracterizando desde a transição democrática.

Entre 1980 e 1994, os problemas fundamentais que a economia brasileira enfrentava eram a crise financeira da dívida externa, a alta inflação inercial e o desequilíbrio das contas públicas. Desde o início dos anos 1990, quando o primeiro e o segundo problema foram

\footnotetext{
do, já que o cálculo do equilíbrio industrial não é preciso, $R \$ 2,90$ por dólar.

3 Primeiro, foi colocado um recolhimento compulsório de $60 \%$ sobre posições vendidas de câmbio por parte de bancos. Segundo, foi criado um IOF de $6 \%$ sobre o financiamento à exportação, taxando inicialmente operações com prazos de 720 dias, que foi aumentado para 1.080 dias. Terceiro, o governo taxou com IOF empréstimos em bônus de até 1800 dias
} 
equacionados, restou o problema fiscal, mas somaramse dois outros que decorreram da estabilização dos preços de 1994: a alta taxa de juros e a taxa de câmbio cronicamente sobreapreciada. Considerados esses três problemas macroeconômicos, o primeiro foi razoavelmente resolvido a partir de 1999, desde que o governo estabeleceu uma meta de superávit primário e passou a alcançá-la; o alto nível de taxa de juros não foi plenamente resolvido, mas nos anos 2000 logrouse um avanço substancial: a taxa de juros deixou de girar em torno de $9 \%$ reais para, em 2012, variar em torno de 3\%; já em relação à taxa de câmbio, não houve avanços: o nível de taxa de câmbio - que torna competitivas as empresas industriais eficientes existentes no Brasil - deveria girar em torno de $\mathrm{R} \$ 2,90$ por dólar, mas vem flutuando em torno de $\mathrm{R} \$ 2,00$.

Por que alcançamos êxito em um problema, algum avanço em outro, e praticamente nenhum no terceiro? Poderíamos tentar responder a esta questão a partir de uma perspectiva política ou ideológica, atribuindo as políticas que foram adotadas pelos presidentes e suas equipes econômicas ao seu grau de liberalismo econômico, mas é preciso também pensar em termos da forma pela qual a sociedade brasileira vê esses três problemas cujo enfrentamento não é trivial, porque envolve interesses de consumidores, ou de empresários, ou de rentistas. Os governantes só se sentem com poder para tentar resolver cada um deles quando se forma um razoável consenso na sociedade civil ou nação sobre a necessidade de resolvê-los, e como fazêlo.

A irresponsabilidade fiscal foi o primeiro problema enfrentado com razoável êxito a partir de 1999, porque a sociedade brasileira se convenceu que uma das causas da alta inflação de 1980-1994 era a irresponsabilidade fiscal. E por isso passou a julgar os políticos também sob esse critério. A redução do patamar de taxa de juros real aconteceu a partir de 2001, porque foi a partir de então que ganhou consistência e intensidade a crítica às taxas de juros exorbitantes que prevaleciam no Brasil desde 1994. Ficou então claro que essas altas taxas não podiam ser explicadas seja pelo risco Brasil seja pela necessidade de combater a inflação, mas simplesmente pelo interesse dos capitalistas rentistas e dos financistas em mantê-las altas. E a sociedade brasileira se convenceu desse fato.

Entretanto, não obstante a crítica a taxa de câmbio sobreapreciada tenha ganho base teórica a partir de 2002, até hoje os avanços foram modestos. Essencialmente porque, no curto prazo, sua correção envolve custos em termos de aumento temporário da inflação, redução temporária dos salários reais, e quebra de empresas excessivamente endividadas em moeda estrangeira. Por esse fato e porque as pessoas têm dificuldade em compreender o quão prejudicial para a economia de um país é um nível de taxa de câmbio sobreapreciada; porque essa sobreapreciação crônica e cíclica atua, conforme a metáfora aludida acima, como um interruptor de luz que desconecta as empresas competentes do mercado tanto externo quanto interno, e, assim, desestimula o investimento e a poupança, e impede o crescimento acelerado que o Brasil precisa ter para realizar o alcançamento.

\section{EMPRESÁRIOS INDUSTRIAIS}

O papel dos empresários industriais é estratégico em um pacto desenvolvimentista. Eles constituíram o grupo dominante no Brasil durante todo o período nacional-desenvolvimentista, e tiveram um papel decisivo na transição democrática - no Pacto Democrático-Popular de 1977. Entretanto, com o fracasso do Plano Cruzado, os empresários industriais se desorientaram e se desorganizaram. Perceberam que a estratégia de industrialização por substituição de importações estava esgotada, e que a alternativa da ortodoxia liberal não era aceitável, mas não sabiam para onde orientar sua ação política. Durante algum tempo, ficaram perplexos. Organizações como a FIESP, a Confederação Nacional da Indústria de repente se viam sem discurso. A onda neoliberal soprava então com toda força, e, diante dela, os empresários industriais sentiam-se sem argumentos perante dos fatos novos. Opuseram-se à abertura comercial que se impunha para tornar a indústria mais competitiva, mas que foi realizada de maneira radical e apressada no governo Collor e levou muitas empresas à falência; já a abertura financeira que representava uma ameaça maior porque implicava a perda do controle da taxa de câmbio não foi então, em dezembro de 1991, percebida como tal pela indústria.

É nesse momento que os 30 maiores empresários industriais nacionais fundam o IEDI (Instituto de Estudos para o Desenvolvimento Industrial) para defender a indústria brasileira. Entretanto, sem contar inicialmente com o apoio de macroeconomistas e cientistas políticos competentes, não perceberam que a ameaça fundamental estava no plano macroeconômico e, em especial, na taxa de câmbio ${ }^{4}$.

\footnotetext{
${ }^{4}$ Lembro-me, nos três primeiros anos da década de 1990, quando participava das reuniões do Conselho Superior de Economia da Fiesp, de alertar os demais membros sobre o problema. Dizia então: "Vocês estão resistindo à abertura comercial, que é inevitável; precisa apenas ser melhor administrada; não estão entretanto percebendo que o principal risco está na taxa de câmbio, que provavelmente se apreciará com o fim da alta inflação, que mais cedo ou mais tarde acontecerá". Em 2001, quando fui convidado para jantar com os dirigentes do IEDI, a primeira coisa que seu líder, Paulo Cunha, me disse, foi lembrar essa frase.
} 
Em vez disso, insistiam na definição pelo governo de uma política industrial como havia havido nos anos 1970. Não percebiam que a política industrial dessa época misturava elementos específicos de política industrial propriamente dita com política macroeconômica. O sistema de tarifas de importação e de subsídios de exportação implicavam uma política macroeconômica cambial na medida em que trazia embutido dentre dele um imposto disfarçado que neutralizava a sobreapreciação da moeda nacional causada pela doença holandesa.

Os empresários estavam perplexos e confusos diante da crise e da mudança de pacto político. Depois de quase sessenta anos de exercício de uma razoável hegemonia política (1930-1987), percebiam que haviam perdido poder, mas, diante da força da ideologia neoliberal justificada "cientificamente" pela teoria econômica neoclássica, não tinham um discurso alternativo a apresentar. Em consequência, muitos se deixaram levar pela ortodoxia liberal e por toda a "modernidade" que ela prometia; ou então vendiam suas empresas para empresas multinacionais e se transformavam em capitalistas rentistas - algo que podia atender a seus interesses, mas prejudicava o país (que, como já vimos, entregava sem contrapartida razoável seu mercado interno para as empresas multinacionais) e reduzia o poder político da indústria.

Nos últimos anos, entretanto, depois que foi ficando claro o fracasso da política econômica proposta pela ortodoxia liberal e o escanteio em que haviam sido colocados, esses empresários, liderados pela Fiesp, o IEDI e a Confederação Nacional da Indústria, começaram a mudar ${ }^{5}$. Sua assessoria macroeconômica melhorou, suas críticas deixaram de se limitar aos exageros da abertura comercial e à falta de uma política industrial para se dirigirem contra os juros altos e o câmbio apreciado. Continuaram, porém, perplexos, provavelmente porque o peso do pensamento hegemônico é muito forte sobre eles. Percebiam o problema, mas hesitavam quanto à solução. $\mathrm{O}$ expresidente da Fiesp, Horácio Piva, por exemplo, declarou a um jornal em 2006: "Estamos todos atônitos, como o resto da sociedade, mas ninguém consegue apresentar um cardápio de opções capaz de fazer com

\footnotetext{
5 A eleição, em 2004, de Paulo Skaf para a presidência da Fiesp e a condução de Paulo Francini para a direção do Departamento de Economia e de Roberto Gianetti Fonseca para o Departamento de Comércio Exterior foram um marco dessa mudança. Os empresários industriais passaram, a partir de então, a adotar uma posição mais clara a favor da mudança da política macroeconômica, aproveitando as críticas que desde 2002 se avolumavam e ganhavam consistência entre os economistas com relação à armadilha da alta taxa de juros e da taxa de câmbio sobreapreciada.
}

que nós nos livremos dessa situação". Por outro lado, insistiam em apontar o Estado e sua burocracia como seus adversários, sem perceber que esta é uma estratégia do Norte para dividir a nação. Cunha (2006), que foi o líder intelectual mais importante dos empresários industriais brasileiros nesse período de crise, indignava-se com a quase-estagnação da economia brasileira, criticava a política macroeconômica, mas afinal concentrava sua crítica no problema do tamanho do Estado, e afirmava que "o Brasil se encontra encurralado por seu Estado". (idem, p.23)

A alternativa à atual política econômica obviamente existe, mas para reconhecê-la é preciso ser também capaz de criticar o Pacto Liberal-Dependente de 1991 - o que os empresários e suas associações, enfraquecidos pela desindustrialização e pela desnacionalização da indústria brasileira, hesitam em fazer. O restabelecimento da aliança dos empresários com a burocracia do Estado é essencial para a retomada do desenvolvimento, mas isto não está claro para eles. Embora saibam da importância do controle do câmbio, não chegam a criticar a política de crescimento com poupança externa; não obstante estejam indignados com a taxa de juros, continuam a atribuir o desequilíbrio fiscal e a carga tributária excessiva exclusivamente ao populismo dos políticos e à ineficiência e ao privilégio da burocracia do Estado, ao invés de compreender que a taxa de juro tem um papel importante em exigir uma carga tributária elevada. Começam, porém, a se dar conta de que o que se montou no Brasil foi um processo de captura do patrimônio do Estado, de violência contra os direitos republicanos dos cidadãos, que beneficia menos a burocracia do Estado e mais os rentistas, o setor financeiro, as empresas monopolistas que privatizaram os serviços públicos, e as empresas multinacionais; que, como os trabalhadores e a burocracia do Estado, também eles, empresários industriais, e, mais amplamente, todo o empresariado dos setores produtivos, estão excluídos do pacto atual. Uma das dificuldades que os empresários enfrentam para compreender esse problema está no fato de que uma parte deles se transformou em rentista, seja porque venderam suas empresas a multinacionais, seja porque as conservaram em estado de dormência, enquanto equilibravam suas contas com os rendimentos financeiros. Esse grupo, porém, embora possa ter influência política, constitui minoria. A grande maioria dos empresários industriais está hoje indignada com a forma pela qual a economia brasileira vem sendo administrada e com os resultados insatisfatórios que vem alcançando em termos de crescimento econômico.

No Brasil, as elites brasileiras, inclusive seus empresários, vivem uma constante ambiguidade - uma 
ambiguidade que as elites dos países asiáticos, por exemplo, não têm. Em alguns momentos, identificamse com um nacionalismo democrático, em outros, tornam-se liberais e dependentes. Se, entretanto, tivéssemos que comparar as elites industriais com as elites intelectuais brasileiras, concluiríamos que as primeiras estão mais identificadas com a nação porque seus interesses estão mais identificados com os interesses nacionais. O desenraizamento dos intelectuais de suas bases nacionais é um problema generalizado. O domínio da universidade estrangeira, principalmente da universidade norte-americana, é enorme. Isto decorre da maior qualidade dessas universidades - algo indiscutível - mas decorre também da mera condição de dependência cultural. Um exemplo disto é a pontuação no sistema Qualis da Capes, o sistema que serve de base para a avaliação das publicações dos pesquisadores brasileiros. De acordo com esse sistema, papers publicados em boas revistas estrangeiras recebem uma pontuação duas a três vezes maior do que pela publicação em uma boa revista acadêmica nacional. $\mathrm{O}$ argumento oferecido é o de que "é mais difícil publicar em revistas estrangeiras" - o que é verdade. Mas, com essa prática, o que a universidade brasileira está fazendo é submeter os padrões de qualidade de sua produção científica às universidades estrangeiras. Que isto se faça com revistas de física, ou de biologia, ou de matemática, é razoável; mas que se faça com as ciências sociais - com a economia, a ciência política - é um sinal de subordinação ideológica grave.

Os empresários têm também problemas de autoafirmação e autoestima nacional, mas nada semelhante ao que acontece na academia. Mesmo entre os intelectuais, porém, começa a haver uma redescoberta da identidade nacional e da Nação. Preocupar-se apenas com a identidade cultural, entretanto, não será suficiente; terão que se preocupar também com a identidade política nacional, que é algo diferente. O Brasil tem, por exemplo, uma identidade cultural mais forte do que a do Canadá, mas a identidade política desse país - a consciência de seu povo de que seu governo existe para defender o trabalho, o conhecimento e o capital nacionais - é muito mais forte.

Um outro sinal importante a abrir espaço para o novo desenvolvimentismo foi a mudança de atitude da imprensa. A mídia, como o Estado, reflete a correlação de forças que existe na sociedade. Quando, a partir da queda do Muro de Berlim, que no Brasil coincidiu com a hiperinflação de fevereiro de 1990 (o mês em que a inflação mensal superou $50 \%$ ), o neoliberalismo e a hegemonia norte-americana se tornaram absolutos no mundo, a imprensa brasileira refletiu esse fato. A ortodoxia liberal foi entendida como a única alternativa responsável de política econômica. Após 2002, porém, na medida em que mudava a sociedade, começou também a mudar a imprensa. Os jornais passaram a dar mais atenção ao custo brutal dos juros sobre o orçamento público, e aos resultados modestos em termos de crescimento da política econômica; ao mesmo tempo, começaram a reportar com mais frequência os argumentos novodesenvolvimentistas.

Existem, portanto, condições, mesmo não sendo as ideais, para que um novo acordo nacional seja informalmente definido entre os brasileiros, que uma nova coalizão política voltada para o desenvolvimento econômico se forme. No governo Lula ocorreram mudanças significativas. Por outro lado, na sociedade, além da insatisfação dos empresários, temos também uma insatisfação crescente na classe média profissional e na dos trabalhadores, e uma atenção cada vez maior dos intelectuais com o problema da Nação. As classes médias percebem as próprias dificuldades, a diminuição das oportunidades para seus filhos, a transformação do Brasil em um país de emigração. A classe média profissional pública, grande e heterogênea, será sempre um parceiro estratégico; hoje dela participam os quadros administrativos, técnicos e intelectuais que constituem o capital de conhecimento de uma Nação. Os trabalhadores, por sua vez, já não vivem uma condição crônica de alto desemprego e salários quase estagnados, e deverão naturalmente participar de um acordo nacional voltado para o desenvolvimento. Certos setores ficarão fora do acordo ou terão seus poderes atuais reduzidos. Penso, particularmente, nos rentistas que vivem de altos juros, nos membros do setor financeiro que recebem comissões dos rentistas para administrar sua riqueza, e nas grandes empresas que administram serviços públicos monopolistas. $\mathrm{O}$ setor financeiro, porém, continuará a desempenhar um papel decisivo na economia nacional, e seus membros acabarão por participar do acordo nacional que se busca construir.

Entre os participantes, o entendimento mais estratégico é o que deve se estabelecer entre os empresários e os burocratas e políticos do Estado. É esse acordo que hoje falta no Brasil, na medida em que os empresários se deixaram influenciar pelo Norte e aceitaram a tese neoliberal de que a fonte de todos os problemas do país está nessa burocracia. Ora, ainda que esta burocracia, como qualquer grupo social, defenda interesses que nem sempre coincidem com os interesses gerais, o fato objetivo é que ela tem um papel estratégico no aparelho do Estado, da mesma forma que os empresários têm um papel estratégico no processo de investimento e de produção. Por outro 
lado, sabemos que o Estado é o instrumento de ação coletiva por excelência com que uma Nação conta. E sabemos que aos políticos (burocratas eleitos), assessorados pelos burocratas de carreira, cabe liderar esse Estado. Logo, um acordo nacional e a definição de uma estratégia nacional de desenvolvimento só serão possíveis se os empresários e os burocratas de Estado souberem superar suas divergências e desconfianças. O grande desenvolvimento que ocorreu no Brasil entre os anos 1930 e os anos 1970 só foi possível porque esse acordo básico existia.

Lograr um acordo nacional significará para seus participantes poder usar o Estado como instrumento de ação coletiva na busca de seus objetivos políticos. Para isso, eles terão que estar dispostos a enfrentar os adversários do acordo. Negam sua necessidade os neoliberais, que declaram desnecessária qualquer estratégia de desenvolvimento, a extrema direita e a extrema esquerda, e as elites globalistas cooptadas pelos países ricos. Nos antigos impérios a dominação se fazia através do uso da força e da colaboração de elites locais; no sistema hegemônico a força foi em grande parte substituída pelo soft power, pelo imenso poder ideológico da universidade, do cinema e da música popular norte-americanos, de forma que se soma à cooptação das elites locais a submissão de amplos setores da sociedade brasileira, admirados com a superioridade científica, tecnológica e cultural dos países ricos. Nesse processo, como os países hegemônicos são democracias complexas, é sempre possível contar com a ajuda de muitos de seus cidadãos, que sabem que afinal vivemos em um mundo só, e que a cooperação deve, em muitos momentos, ter precedência sobre a competição.

\section{CONCLUSÕES}

Em síntese, a coalizão de classes hoje dominante no Brasil não pode mais ser definida por um pacto liberal-dependente, como o foi entre 1990 e meados dos anos 2000, mas não se pode afirmar com certeza que se tenha transformado em um pacto nacionalpopular. Hoje a hegemonia neoliberal dos anos 1990 é coisa definitivamente do passado. O Estado deixou de ser a fonte de todos os males, para ser o instrumento por excelência de ação coletiva da nação. O papel providencial do Estado em enfrentar e minorar as consequências da Crise Financeira Global de 2008 em todo o mundo deixou muito claro esse papel e esse poder do Estado. Para boa parte das classes dirigentes brasileiras, não faz mais sentido entender o mercado como uma alternativa ao Estado; o mercado é apenas uma instituição baseada na competição complementar à coordenação ou regulação do Estado, da lei. O desenvolvimentismo deixou de ser confundido com o populismo e o estatismo. As privatizações e a diminuição das despesas públicas deixaram de ser a solução para todos os problemas. Como também deixou de fazer sentido o keynesianismo vulgar que vê no aumento dos gastos do governo também a solução de todos os males. O controle da entrada de capitais e mais amplamente a adoção de uma taxa de câmbio flutuante, mas administrada, passou a ser a política monetária do país. A política industrial voltou a ser um dos instrumentos básicos da promoção do desenvolvimento econômico.

Luiz Werneck Vianna (2007) reconheceu a mudança ocorrida - o fato de que agora participavam do governo as múltiplas frações da burguesia brasileira, lado a lado com sindicalistas, intelectuais, e movimentos como o MST, mas ao invés de ver nisto a formação de uma nova coalizão de classes, adotou uma visão crítica segundo a qual "a composição pluriclassista do governo, portanto, se traduz em uma forma de Estado de compromisso, abrigando forças sociais contraditórias entre si - em boa parte estranhas ou independentes dos partidos políticos, cujas pretensões são arbitradas no seu interior, e decididas, em última instância, pelo chefe do Poder Executivo." Mas um pacto político é sempre um "Estado de compromisso", porque para se entenderem as frações de classe devem necessariamente fazer concessões mútuas. E não há razão para se transformar Lula em um presidente todo poderoso, que centralizava todo o poder. Apesar das diferenças de matriz teórica dos dois autores, a afirmação de Vianna parece inspirar-se na tese de Guillermo O’Donnell (1991) segundo a qual os novos regimes democráticos nos países da América Latina, após as transições democráticas dos anos 1980, se transformaram em "democracias delegadas" nas quais todo o poder é delegado pela sociedade ao chefe do Estado. Ora, esta tese de centralização do poder é meia verdade. Os regimes presidencialistas têm inspiração monárquica e implicam, sempre, um poder grande para o chefe do Estado, mas à medida em que a democracia avançou nesses países e principalmente no Brasil, porque a sociedade civil ganhou mais autonomia e porque as instituições democráticas se consolidaram, o poder do presidente foi limitado. A democracia delegada é compatível com o primeiro estágio da democracia - o estágio da democracia de elites ou schumpeteriana, na qual os políticos apenas se relacionam com os eleitores no momento da eleição e ainda assim, de maneira limitada. A democracia brasileira já atingiu um segundo estágio - a da democracia de opinião pública ou democracia de massas - na qual as massas manifestam nas eleições seus interesses de forma concreta.

Sociedade e governo estão, assim, em mudança no Brasil. Tanto o governo Lula quanto o governo Dilma 
não se auto-identificaram como desenvolvimentistas, mas suas políticas caminharam nessa direção, e um de seus principais líderes políticos do PT, Aloisio Mercadante, em sua tese de doutoramento defendida em 2010 (MERCADANTE, 2010), nos últimos dias do governo Lula, não hesitou em denominá-la "As Bases do Novo Desenvolvimentismo no Brasil". O governo Lula deu os primeiros passos no sentido de construir um acordo nacional desenvolvimentista, a presidente Dilma Rousseff está caminhando mais determinadamente na direção de uma estratégia novodesenvolvimentista, como se pode ver pela batalha que montou para baixar a taxa de juros e depreciar o real. Entretanto, a depreciação do real só chegará próxima da taxa de câmbio de equilíbrio industrial quando o governo tiver condições políticas de taxar as commodities. Os produtores afinal nada pagarão por isso, porque o que pagarem em imposto lhes será devolvido sob a forma de depreciação, mas não será fácil estabelecer um imposto dessa natureza no Brasil. É o desafio maior que a sociedade brasileira enfrenta hoje no plano econômico. Há muitos outros desafios, inclusive o desafio moral, o social, e o ambiental mas esses desafios o Brasil vem enfrentando como pode, enquanto que o desafio do imposto sobre as exportações não está ainda claro para a sociedade brasileira; não foi possível ainda se colocar o problema na agenda nacional; não está claro para praticamente ninguém porque ele é essencial para o Brasil voltar a crescer de forma acelerada.

Luiz Carlos Bresser-Pereira (bresserpereira@gmail.com) é Doutor em Economia pela Universidade de São Paulo (USP) e Professor na Fundação Getúlio Vargas (FGV-SP).

\section{REFERÊNCIAS BIBLIOGRÁFICAS}

AB'SÁBER, T. 2011. Lulismo, Carisma Pop e Cultura Anticrítica. São Paulo: Hedra.

COUTINHO, C. N. 2010. Hegemonia da pequena política. In: OLIVEIRA, F.; BRAGA, R. \& RIZEK, C. (orgs.). Hegemonia às avessas. Economia, política e cultura na era da servidão financeira. São Paulo: Boitempo.

CUNHA, P. 2006. Dissecando a integral do erro. In: BRESSER-PEREIRA, L. C. (org.). Economia brasileira na encruzilhada. Rio de Janeiro: FGV.

FILGUEIRAS, L.; PINHEIRO, B.; PHILIGRET, C. \& BALANCO, P. 2010. Modelo liberal-periférico e bloco de poder: política e dinâmica macroeconômica nos governos Lula. In: MAGALHÃES, J. P. A. (org.). 2010. Os anos Lula: contribuições para um balanço crítico 2003-2010. Rio de Janeiro: Garamond. Disponível em: http:// www.ie.ufrj.br/hpp/intranet/pdfs/ filgueiras_et_al_2010_otim.pdf. Acesso em: 29.jul.2013.

MARCONI, N. 2012. The industrial equilibrium exchange rate in Brazil: an estimation. Revista de Economia Política. 2012, vol.32, n.4, p. 656-669. Disponível em: http://www.scielo.br/pdf/rep/ v32n4/07.pdf Acesso em: 14.set.2013.
MERCADANTE, A. 2010. As bases do novo desenvolvimentismo no Brasil. Campinas. Tese (Doutorado em Economia). Universidade Estadual de Campinas.

O'DONNELL, G. 1991. Democracia Delegativa? Novos Estudos, São Paulo, n. 31, p. 25-40, out. Disponível em: http://pt.scribd.com/doc/22584776/ODonnel-1991-Cebrap-Democracia-Delegativa. Acesso em: 20.jul.2013.

OLIVEIRA, F. 2010. Hegemonia às avessas: deciframe ou te devoro! In: OLIVEIRA, F.; BRAGA, R. \& RIZEK, C. (orgs.). Hegemonia às avessas. Economia, política e cultura na era da servidão financeira. São Paulo: Boitempo.

SINGER, A. 2009. Raízes sociais e ideológicas do Lulismo. Novos Estudos, São Paulo, n. 85, p. 83104, nov. Disponível em: http://www.scielo.br/pdf/ nec/n85/n85a04.pdf. Acesso em: 30.jul.2013.

2011. Realinhamento eleitoral e mudança política no Brasil. São Paulo. Tese (Livre-Docência). Universidade de São Paulo.

WERNECK VIANNA, L. 2007. O estado novo do PT. La Insignia, 13.jul. Disponível em: http:// www.lainsignia.org/2007/julio/ibe_007.htm. Acesso em: 29.jul.2013. 
ENTREPRENEURS, THE PT GOVERNMENT, AND DEVELOPMENTALISM.

\section{Luiz Carlos Bresser-Pereira}

This article discusses the problem of developmentalism in Brazil in PT governments. To what extent, under Lula and Dilma, industrial entrepreneurs distinguish themselves the capitalist rentiers and form, with the workers and the public bureaucracy, a developmental class coalition? My hypotheses is derived from my theory about the role of class coalitions, which may eihter be developmental, or liberal. The data are available in the press. I believe that the efforts of PT governments to obtain the support of a developmental class coalition are clear, but is is also clear the relative failure of this effort, in so far as the main obstacle to the development of the Brazilian economy (the chronically sobreapreciado rates) was not overcome, due to lack of support in the Brazilian society for a large and permanent depreciation.

KEYWORDS: developmentalism; class coalitions; business entrepreneurs; economic liberalism; PT government. 